\title{
Humanities in Predoctoral Dental Education: A Scoping Review
}

\author{
Kyriaki C. Marti, Anastassios I. Mylonas, Mark MacEachern, Larry Gruppen
}

Abstract: Health humanities usually includes such disciplines as philosophy, ethics, history, literature, performing arts, and cultural anthropology. The aims of this scoping review were, first, to search the published literature for references to the humanities in predoctoral dental education and, second, to determine if any research studies found that introducing humanities in dental education improved the overall profile of dental graduates. Literature searches were run in Ovid MEDLINE, Embase, ERIC, CINAHL, and Dentistry and Oral Sciences Source. A total of 248 articles were included in the review, with inclusion criteria comprising the areas of the curriculum, the scope of humanities, and predoctoral dental education. Of those articles, 101 referred in a targeted way to ethics in predoctoral dental education, while others mainly referred to the humanities in general or pointed out the role and place of humanities topics in predoctoral dental curricula. Topics covered included professional ethics, music, narrative learning, theater, art, communication skills, empathy, emotional intelligence, and cultural competence in the context of general humanistic education. The review found limited evidence of a clear impact, either short-term or long-term, of humanities education in predoctoral dental education. Reflections on humanistic education in the practice of clinical dentistry were sparse, as mainly documented by development of the ideal dentist-patient relationship, enhancement of empathy for patients, and most importantly, construction of professional moral values.

Kyriaki C. Marti, DMD, MD, MHPE, PhD, CHSE, FEBOMFS, is Clinical Assistant Professor, Departments of Oral and Maxillofacial Surgery, Periodontics and Oral Medicine, Cariology, Restorative Sciences, and Endodontics, University of Michigan School of Dentistry; Anastassios I. Mylonas, DMD, PhD, PhD, MD, is Research Associate, Clinical Instructor, and Associate Director, Departments of History and Philosophy of Medicine and Oral and Maxillofacial Surgery, Schools of Medicine and Dentistry, National and Kapodistrian University of Athens, Metropolitan Hospital; Mark MacEachern, MLIS, is an Informationist in Research and Informatics, Taubman Health Sciences Library, University of Michigan; and Larry Gruppen, PhD, is Professor, Department of Learning Health Sciences, University of Michigan Medical School. Direct correspondence to Dr. Kyriaki C. Marti, University of Michigan School of Dentistry, 1011 N. University Ave., Ann Arbor, MI 48109; kyriaki@med.umich.edu.

Keywords: dental education, humanities, ethics and professionalism, cultural competence, academic integrity, curriculum

Submitted for publication 12/26/18; accepted 5/17/19; first published online 7/8/19 doi: $10.21815 / J D E .019 .126$

$\mathrm{W}$ e believe there is a need to develop a more humanistic model of education by integrating the study of humanities into predoctoral dental curricula. Although we have observed that a few dental schools have implemented humanities in their dental education, we also believe there is an overall acceptance that humanities may contribute decisively to the increase of dental students' professionalism, as reflected in the development of holistically oriented dental professionals and not merely technically qualified health care providers. The humanities include such disciplines as philosophy, ethics, history, literature, and the performing arts. ${ }^{1}$ Brody defined medical humanities or health humanities as "a combination of its relevant disciplines - ethics and philosophy, religious studies, history, literature, and so forth." ${ }^{2}$ Defining humanities in health professions education may be challenging; still, Hunt recognized it "as a means to emphasize, celebrate, and critically explore the human aspect of medicine." ${ }^{3}$

According to the Commission on Dental Accreditation (CODA) standards for dental education, a humanistic environment "inculcates respect, tolerance, understanding, and concern for others and is fostered by mentoring, advising, and small group interaction." ${ }^{\text {D }}$ Due to the recognition that the concept of a profession has strong cultural components ${ }^{5}$ and since "culture is the collective mutually shaping patterns of norms, values, assumptions, beliefs, standards, and attitudes that guide the behavior of individuals and groups, whether those groups be families, religions, races, geographic regions, nations, businesses, or professions," we believe the introduction of humanities into predoctoral dental curricula is a necessity for the academic dental community. The development of aspiring and holistically trained future dental professionals rests on the 
belief that "education is a reflective experience that can lead to behavioral change." On the other hand, we have heard the opinion that while the advent of technological interventions is beneficial, technology may become a barrier to interchange between dentists and patients if dental professionals treat patients as "cases" of oral diseases rather than individuals whose oral health is compromised.

The aims of this scoping review were, first, to search the published literature for references to the humanities in predoctoral dental education and, second, to determine if any research studies found that introducing humanities in dental education improved the overall profile of dental graduates. A scoping review is used to address broad areas of studies in which various research designs have been used in order to survey the extent of publications on the topic or identify research gaps in the literature, as implemented in previous scoping reviews. ${ }^{8,9}$

\section{Methods}

We systematically searched the literature for publications relating to humanities in predoctoral dental education. The search was performed by one of the authors (M.M.) who has experience developing systematic review searches. The search was initially run in December 2016 and rerun in July 2017 in Ovid MEDLINE, Ovid MEDLINE In-Process \& Other Non-Indexed Citations, Ovid MEDLINE Epub Ahead of Print, Embase.com, ERIC via FirstSearch, and Dentistry and Oral Sciences Source via EBSCOhost. Non-English studies were excluded from the results. Each search consisted of a set of humanities terms crossed with a set of dental education terms. Controlled vocabularies, such as Medical Subject Headings, were used whenever possible and always complemented with title or abstract keywords (Table 1). Reference lists of studies were also checked.

\section{Table 1. Keywords used for each database}

Ovid MEDLINE, Ovid MEDLINE In-Process \& Other Non-Indexed Citations, Ovid MEDLINE Epub Ahead of Print

Copy and pastable: (exp humanities/ed and (exp education, dental/ or exp schools, dental/ or exp students, dental/)) or ((humanities/ or exp *art/ or exp *literature/ or exp *philosophy, dental/ or (humanities or art or artistic or literature* or philosoph* or painting* or poet* or poem* or drawing or illustrat* or cartoon* or metaphor* or myth* or personal narrative* or music* or theatre* or theater*).ti.) and (exp education, dental/ or (dent* adj3 (educat* or curricul* or school*)).ti.)) and english.la

Line by line:

1. exp humanities/ed

2. exp education, dental/

3. exp schools, dental/

4. exp students, dental/

5. 1 and ( 2 or 3 or 4$)$

6. humanities/

7. exp *art/

8. $\exp *$ literature/

9. exp *philosophy, dental/
10. art.ti
11. artistic.ti
12. cartoon*.ti
13. drawing.ti
14. humanities.ti
15. illustrat*.ti
16. literature*.ti

9. exp *philosophy, dental/

14. humanities.

15. illustrat*.ti

\author{
25. theatre*.ti \\ 26. or/6-25 \\ 27. exp education, dental/ \\ 28. (dent* adj3 (educat* or \\ curricul* or school*)).ti. \\ 29. or/27-28 \\ 30. 5 or (26 and 29) and \\ english.la.
}

\section{Embase.com}

Copy and pastable: 'humanities'/mj OR 'arts and illustration'/exp/mj OR 'history'/exp/mj OR humanities:ti OR art:ti OR artistic:ti OR philosoph*:ti OR poet*:ti OR poem*:ti OR paint*:ti OR literature*:ti OR drawing:ti OR illustrat*:ti OR cartoon*:ti OR metaphor*:ti OR myth*:ti OR 'personal narrative':ti OR 'personal narratives':ti OR music*:ti OR theatre*:ti OR theater*:ti AND ('dental education'/ exp/mj OR 'dental student'/exp/mj OR (dent* NEAR/3 (educat* OR school* OR curricul* OR student*)):ti) AND [english]/lim

Line by line:
1. 'humanities'/mj
2. 'arts and illustration'/exp/mj
3. 'history'/exp/mj
4. humanities:ti
5. art:ti
6. artistic:ti
7. cartoon*:ti
8. drawing:ti
9. illustrat*:ti

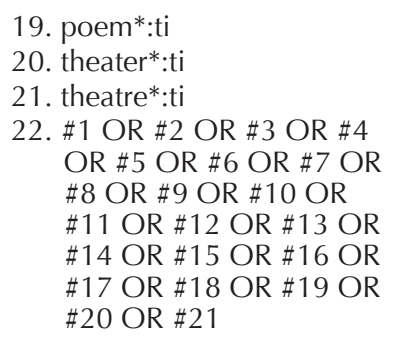

23. 'dental education'/exp/mj

24. 'dental student'/exp/mj

25. (dent* NEAR/3 (educat* OR school* OR curricul* OR student*)):ti

26. \#23 OR \#24 OR \#25

27. \#22 AND \#26 AND

[english]/lim 


\section{Table 1. Keywords used for each database (continued)}

\section{ERIC via FirstSearch}

Copy and pastable: (su: dentistry OR su: dental w schools OR ti: dent*) AND (su: humanities OR ti: humanities OR ti: art OR ti: artistic OR ti: philosoph* OR ti: poet* OR ti: poem* OR ti: paint* OR ti: literature* OR ti: drawing* OR ti: illustrat* OR ti: cartoon* OR ti: metaphor* OR ti: personal w narrative OR ti: personal w narratives OR ti: myth* OR ti: music* OR ti: theatre* OR ti: theater*)

Line by line:

$\begin{array}{ll}\text { 1. su: dentistry } & \text { 6. ti: artistic } \\ \text { 2. (su: dental w schools) } & \text { 7. ti: cartoon* } \\ \text { 3. ti: dent* } & \text { 8. ti: drawing } \\ \text { 4. \#1 OR \#2 OR \#3 } & \text { 9. ti: illustrat* } \\ \text { 5. su: humanities } & \text { 10. ti: literature* } \\ \text { 6. ti: humanities } & \text { 11. ti: metaphor* } \\ \text { 5. ti: art } & \text { 12. ti: music* }\end{array}$

13. ti: myth*
14. ti: paint*
15. ti: personal w narrative
16. ti: personal $w$ narratives
17. ti: philosoph*
18. ti: poem*
19. ti: poet*
20. ti: theater*

21. ti: theatre*

22. \#5 OR \#6 OR \#7 OR \#8 OR \#9 OR \#10 OR \#11 OR \#12 OR \#13 OR \#14 OR \#15 OR \#16 OR \#17 OR \#18 OR \#19 OR \#20 OR \#21

23. \#4 AND \#22

\section{CINAHL via EBSCOhost}

Copy and pastable: (MM "education, dental" OR MM "students, dental" OR MM "schools, dental" OR (TI dent* AND (TI educat* OR TI curricul* OR TI school* OR TI student*)) ) AND ( MM "liberal arts+" OR TI humanities OR TI art OR TI artistic OR TI philosoph* OR TI poet* OR TI poem* OR TI paint* OR TI literature* OR TI drawing OR TI illustrat* OR TI cartoon* OR TI metaphor* OR TI myth* OR TI "personal narrative" OR TI "personal narratives" OR TI music* OR TI theatre* OR TI theater*)

Line by line:

S1. MM "education, dental"

S2. MM "students, dental"

S3. MM "schools, dental"

S4. TI dent*

S5. TI educat*

S6. TI curric*

S7. Tl student*

S8. TI school*

S9. S1 OR S2 OR S3 OR (S4 AND

(S5 OR S6 OR S7 OR S8))

\section{DOSS via EBSCOhost}

S1. SU "dental schools"

S2. SU "dental students"

S3. TI dent*

S4. TI educat*

S5. TI curric*

S6. TI school*

S7. TI student*

S8. S1 OR S2 OR (S3 AND

(S4 OR S5 OR S6 OR S7))
S10. MM "liberal artst"

S12. TI humanities

S13. Tl art

S14. TI artistic

S15. TI cartoon*

S16. TI drawing

S17. TI illustrat*

S18. TI literature*

S19. TI metaphor*

S9. SU humanities

S10. TI humanities

S11. Tl art

S12. TI artistic

S13. TI cartoon*

S14. TI drawing

S15. TI illustrat*

S16. TI literature*

S17. TI metaphor*
S20. TI music*

S21. TI myth*

S22. TI paint*

S23. TI "personal narrative"

S24. TI "personal narratives"

S25. TI philosoph*

S26. TI poem*

S27. TI poet*

S28. TI theater*

S18. TI music*

S19. TI myth*

S20. TI paint*

S21. TI "personal narrative"

S22. TI "personal narratives"

S23. TI philosoph*

S24. TI poem*

S25. TI poet*

S26. TI theater*
S29. TI theatre*

S30. (S10 OR S11 OR S12 OR

S13 OR S14 OR S15 OR

S16 OR S17 OR S18 OR

S19 OR S20 OR S21 OR

S22 OR S23 OR S24 OR

S25 OR S26 OR S27 OR

S28 OR S29)

S29. S9 AND S30
S27. TI theatre*
S28. (S9 OR S10 OR S11 OR
S12 OR S13 OR S14 OR
S15 OR S16 OR S17 OR
S18 OR S19 OR S20 OR
S21 OR S22 OR S23 OR
S24 OR S25 OR S26 OR
S27)
S29. S8 AND S28
In the initial screening process, we identified 760 articles (Figure 1). A secondary review performed by two of the authors (K.M. and A.I.M.) identified 109 additional articles. The total 869 articles were identified based on abstract and/or title. Using the exclusion and inclusion criteria in Table 2 (adapted for dental education from Ousager and Johannessen ${ }^{10}$ ), we screened all 869 articles and retrieved 272 of them. We carefully read all these articles. In cases in which a full-text version was not available through the University of Michigan library online system, only the abstract was read thoroughly.
We eliminated 24 articles as obviously irrelevant or because no data were obtained (except for the title or key words). Finally, 248 articles were included in our final review and categorization.

To define the relation of each publication to the humanities, we used the typology in Ousager and Johannessen's study. ${ }^{10}$ With that typology, we labeled all articles according to type of publication, sector of the major field of humanities treated, any suggested outcome derived from the specified program or activity, and general tone, attitude, or message. 


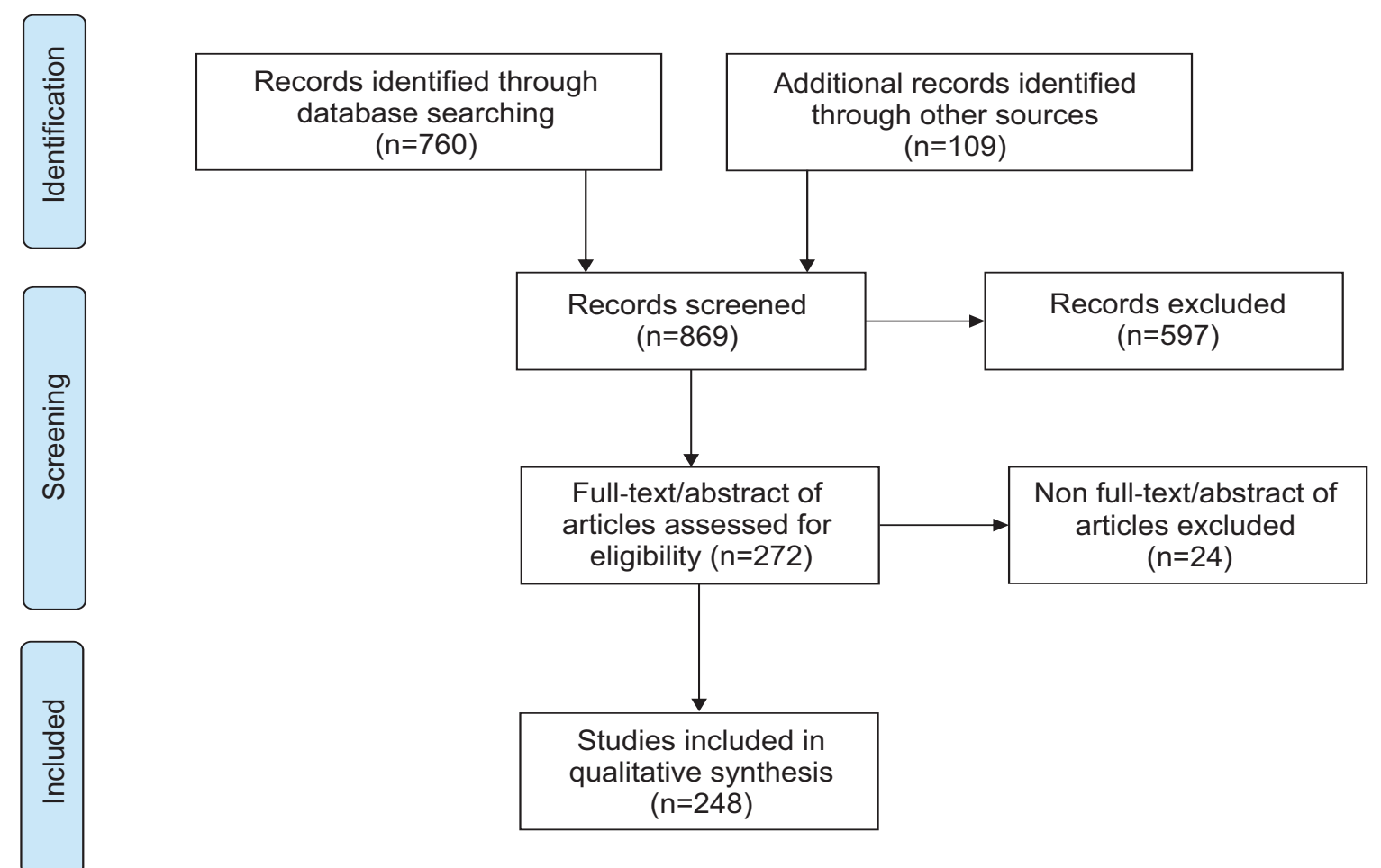

Figure 1. Flow diagram showing screening process used in review

Table 2. Inclusion and exclusion criteria

\begin{tabular}{ll} 
Parameters & Inclusion Criteria \\
\hline $\begin{array}{l}\text { Intervention, program, course, } \\
\text { curriculum }\end{array}$ & $\begin{array}{l}\text { Viewpoints, descriptions, evaluations, reports } \\
\text { Planned, current, completed activities }\end{array}$ \\
Subject matter area & $\begin{array}{l}\text { Humanities in general, aesthetics, arts, health } \\
\text { communication, creative writing, culture, discussion, } \\
\text { drama/theater, epistemology, ethics, films, gender } \\
\text { studies, history, literature, music, narratives, religion, } \\
\text { spirituality }\end{array}$
\end{tabular}

Predoctoral dental education Related only to predoctoral dental education
Exclusion Criteria

Admission

Clinical/therapeutic uses

Other general topics

Law, social sciences, and economics

Other health professions

Advanced dental education

Note: Criteria were adapted for dental education from Ousager J, Johannessen H. Humanities in undergraduate medical education: a literature review. Acad Med 2010;85(6):988-98.

\section{Results}

After we applied the inclusion criteria, 248 articles resulted for the analysis. We organized these articles into the following categories: benefits of humanities in dental education, $\mathrm{n}=57$ (Table 3); course descriptions or assessments, $\mathrm{n}=85$ (Table 4 ); evidence of outcomes (if any), $\mathrm{n}=66$ (Table 5); and attitudes (drawbacks/negative comments or positive/optimistic comments), $\mathrm{n}=40$ (Table 6).

Out of the 248 articles, only 28 referred in a targeted way to humanities in predoctoral dental curricula. The great majority of articles $(n=101)$ focused on professional ethics in dentistry, regarding such topics as principles, education, and decision making; role-modeling by faculty; oath ceremonies and code of professional conduct; and concern about a decline 
Table 3. Articles regarding benefits of humanities to dental education (DE) $(n=57)$

Article/First Author, Reference Number

Karimbux, reference 67

ADEA statement on professionalism in DE, reference 54

Rosenblum, reference 29

Reynolds EC. Dealing with ethical challenges when leading student mission trips. J Am Dent Assoc 2014;145(5):486-7.

Tyagi, reference 5

Curtis, reference 12

Cederberg RA, Valenza JA. Ethics and the electronic health record in dental school clinics. J Dent Educ 2012;76(5):584-9.

Lantz MS, Zarkowski P. More on dental school Ethics and DE ethics. J Mich Dent Assoc 2008;90(12):12-3.

Quick KK. My life as a dentist and ethicist: an Ethics and faculty experiment in creative nonfiction. J Am Coll Dent 2011;78(3):31-2

Nash DA. Ethics and the "seasons of my life" as a dental educator. J Am Coll Dent 2011;78(3):18-23.

Graskemper J. Ethics is how you respond to life. J Am Coll Dent 2011;78(3):14-7.

Nash DA. Ethics, empathy, and the education of dentists. J Dent Educ 2010;74(6):567-78.

Meru MC. Following your moral compass: ethics in dental school. Ethic Decision Making Dent 2014:13.

Schwartz, reference 47

Hughes PJ, et al. Academic integrity in dental school: a call to action. J Am Coll Dent 2009;76(2):31-7.

Ardenghi DM. Dentists' ethical practical knowledge: a critical issue for dental education. Eur J Dent Educ 2009;13(2):69-72.

Zielinski TJ. Doing nothing about ethics. J Mich Dent Assoc 2008;90(11):16-7.

Rosenblum A. A student-initiated movement toward a more positive ethics. J Am Coll Dent 2008;75(2):11-3.

Morton, reference 21

Loftis B. Pointing the profession in the right direction: positive ethical movements among dental students and education. J Am Coll Dent 2008;75(2):18-21.

Lantz MS, Zarkowski P. Can ethics be taught? What students are learning at our two dental schools. J Mich Dent Assoc 2008;90(9):28-35. and ethics in DE records (EHRs)

Ethics in DE

Ethics in DE

Ethics in DE

Ethics in DE

Humanistic DE in DE

Ethics in DE
Area of Humanities

Publication Type/Contents

Ethics and professionalism in DE Editorial

Professionalism in DE

Statement by ADEA Task Force on Professionalism in DE

Emotional intelligence

Ethics and global DE

Ethics and professionalism in DE

Narrative medicine in DE

Ethics and electronic health

Ethics and DE

Ethics and professionalism in DE

Empathy and ethics in DE

Ethics and oath in DE

Academic integrity

Ethics and academic integrity
Essay recommending more emotional, noncognitive input to ethical decision process in DE and practice

Commentary by member of ADA Council on Ethics, Bylaws, and Judicial Affairs

Discussion of significance of ethics and professionalism in DE

Essay on importance of narrative training in communication among health professionals

Exploration of ethical issues related to EHRs in dental schools

Commentary

Reflection on experiences of a faculty member teaching ethics to dental students

Essay on emergence of author's personal and professional interest in ethics ethics in dentistry through ethics and law

Essay on teaching ethics and empathy in DE

Extensive presentation of issues related to ethics education in dental school

Analysis of dental school oaths taken by students in U.S., Canada, and Puerto Rico

Position paper on academic misconduct in dental school and how educators can develop strategies to address issue

Essay on how DE can foster development of dentists' ethical practical knowledge

Commentary on dental school ethics

Description of student-initiated ethics club

Dental student's essay on benefits of humanistic education

Description of proactive role of American Student Dental Association in addressing academic dishonesty and other ethical problems

Ethics teaching at two dental schools in Michigan 


\section{Table 3. Articles regarding benefits of humanities to dental education (DE) ( $n=57)$ (continued)}

Article/First Author, Reference Number

Lucas-Perry E, Akinkugbe A. Bio-ethics in dental education: dental public health residents' perspective. Ethics Biol Eng Med $2011 ; 2(2)$.

Abelson SH. Positive ethics and dental students. J Am Coll Dent 2008;75(2):27-8.

Lingen MW. Tales of academic dishonesty and what do we do about it? Oral Surg Oral Med Oral Pathol Oral Radiol Endod 2006;102(4):429-30.

Nash, reference 46

Botto RW. Addressing the marketplace mentality and improving professionalism in dental education. J Dent Educ 2007;71(2):217-21.

Rosenblum A. Our next generation: dental student ethics and its potential influence on the profession. J Calif Dent Assoc 2013;41(7):519-23.

Beemsterboer PL. Developing an ethic of access to care in dentistry. J Dent Educ 2006;70(11):1212-6.

Peltier BN, et al. White coat principles. J Am Coll Dent 2004;71(4):53-6.

Holden ACL. Reflections on the encouragement of altruism in dental education. Eur J Dent Educ, 7 Dec. 2016.

Hunt LM. Dentist's oath of pledge. J Dent Educ 1997;61(8):650.

Berk, reference 40

Bridgman A, et al. Teaching and assessing ethics and law in the dental curriculum. Br Dent J 1999;187(4):217-9.

Tankersley KC. Academic integrity from a student's perspective. J Dent Educ 1997;61(8):692-3.

McCarthy G. Standardization of ethics education and use of the Hippocratic oath for health science students. J Dent Educ 1997;61(8):649.

Peltier B, Dugoni AA. A four-part model to energize ethical conversation. J Calif Dent Assoc 1994;22(10):23-6.

Christen AG, et al. Why should history be taught in dental school? Bull Hist Dent 1988;36(2):127-32.

Ozar DT. Formal instruction in dental professional ethics. J Dent Educ 1985;49(10):696-701.

Engelhardt HT Jr. Humanism and the profession(al). J Dent Educ 1985;49(4):202-6.

Neidle EA. Dentistry-ethics-the humanities: a three-unit bridge. J Dent Educ 1980; 44(12):693-6.
Area of Humanities

Ethics in DE

Ethics and academic integrity of dental students

Academic integrity

Ethics in DE

Professionalism in DE

Ethics and professionalism in DE

in dension of limita

Professionalism and ethics in DE

Essay on how DE enhances public service side of professionalism prior to admission and during and after dental school

Professionalism and ethics in DE

Proposal for eight white coat ceremony principles

Altruism in DE

Commentary on need for reform of dental schools' environment to promote altruism

Ethics in DE

Letter on dentist's oath

Ethics in DE

Ethics and law in DE

Academic integrity

Ethics in DE

Philosophical ethics in DE

History in DE

Ethics in DE

Humanistic education

Humanities and ethics in DE

Overview of trends in ethics teaching in dental schools

General Dental Council recommendations on importance of ethics and law in dental curricula

Student essay on professional integrity in DE

Hippocratic oath in DE

Description of a four-part model on ethics

Commentary

Essay on need for formal instruction in dental ethics

Description of the humanistic professional

Essay on history, philosophy, and study of

civilization as essential parts of DE 
Table 3. Articles regarding benefits of humanities to dental education (DE) $(n=57)$ (continued)

Article/First Author, Reference Number

Vergnes, reference 59

Lovas, reference 58

Curtin S, Trace A. Exploring motivational interviewing and its philosophical alignment to an undergraduate behavioral science program in dentistry. Eur J Dent Educ 2013;17:2,8.

Chalfin $\mathrm{H}$. Ethics and professionalism: the past, present, and future. J Am Coll Dent 2006;73(1):42-7.

McAndrew, reference 61

Nadershahi, reference 27

Masella, reference 51

Spallek, reference 62

Spallek, reference 63

Carey, reference 28

Bertolami CN. Further dialogue on ethics in dental education. J Dent Educ 2005;69(2):229-31.

Hoffmann BM, Eriksen HM. The concept of disease: ethical challenges and relevance to dentistry and dental education. Eur J Dent Educ 2001;5:2-8.

Jenson LE. Why our ethics curricula do work. J Ethics in DE Dent Educ 2005;69(2):225-8.

Graham BS. Educating dental students about oral health care access disparities. J Dent Educ 2006;70(11):1208-11.

Zijlstra-Shaw S, et al. Assessing professionalism in dental education: the need for a definition. Eur J Dent Educ 2012;16(1):e128.

Simon L. Narrative and patient care. J Am Dent Assoc 2015;146(9):654.

Karimbux NY. From digital native to health care professional. J Dent Educ 2013;77(11):1401.
Area of Humanities

Narrative learning

Mindfulness in DE

Motivational interviewing (MI)

in DE

Ethics and professionalism in DE

Social media in DE

Humanism in DE

Professionalism in DE

Social media in DE

Social media in DE

Communication skills in DE

Ethics in DE

Ethics in dental and medical education

Cultural competence in DE

Professionalism in DE

Narrative dentistry

Letter

Media and professionalism in DE
Publication Type/Contents

Essay on use of narrative medicine to cultivate patient-centered dentistry

Review of use of mindfulness in teaching professionalism in DE

Review of application of $\mathrm{MI}$ in oral health in predoctoral education

Retrospective on foundation of ethics and its importance as touchstone of professionalism

Description of range of Web 2.0 technologies available for use in DE and their potential problems

Editorial on creating culture of humanism in dental school

Essay on implementation of professionalism curricula in DE

Discussion of how social media has changed DE from personal, professional, and legal perspectives

Discussion of development and assessment of knowledge, skills, attitudes, and behaviors needed for dentists to use social media

Systematic review of quality of evidence in communication skills training for dental students

Response to critiques to his prior article

Position paper on considerations in ethics education in dentistry and medicine

Response to prior article

Essay on importance of educating students about access issues

Literature review

Editorial on use of media in educating dental students about professionalism

Note: Those articles that appear in the references are referred to by last name of first author and reference number; those articles not in the references include full citation. 
of ethics and rise of cynicism. We also identified those articles that addressed specific areas or aspects of the humanities, as summarized in the subsequent sections.

\section{Music and Narrative Learning}

Anyanwu investigated the ability of background music to enhance the cognitive abilities of students during anatomy courses in the cadaver dissection laboratory. ${ }^{11}$ Curtis referred to application of narrative medicine to health care ethics and stated that learning how to receive and tell stories, practiced through close reading, group discussion, and written response, may also facilitate ethical reflection and inquiry. ${ }^{12}$ Kieser initiated storytelling as an educational method, nurturing reflective learning in an anatomy course. ${ }^{13}$

\section{Theater}

The "forum theater" was described in two studies as a novel method for teaching communication skills to medical or dental students, demonstrating particularly inappropriate communication skills rather than inappropriate attitudes. ${ }^{14,15}$ Krüger et al. described the lessons learned from using this method for teaching communication skills. ${ }^{14}$

Bourke described the use of theater as a strategy for oral health education in schools, suggesting that theater is a useful medium for health education of young people. ${ }^{16} \mathrm{Al}$-Ahmad found this methodology was a good approach for training dental students in oral surgery, although the use of this active learning methodology was extremely limited. ${ }^{17}$ BrettMacLean et al. tried to explore professionalism in dental and medical education through forum theater, originally created by Brazilian theater director $\mathrm{Au}$ gusto Boal in 1985 as an approach for promoting dialogue between the audience and those performing on stage ("Theater for the Oppressed")..$^{15}$ In forum theater, a short scene is performed and repeated while audience members are invited to intervene and offer options to address a problematic situation. These investigators introduced forum theater in an "Introduction to Medicine \& Dentistry" course and described how they successfully engaged first-year medical or dental students to reflect on professionalism issues relevant to their experiences using theater.

\section{Empathy}

Schwartz and Bohay raised the issue of the importance of empathy in the development of dental students' professionalism with the use of patient videos and interpersonal communications as educational methodologies. ${ }^{18}$ Personal construct psychology attracted the interest of another author, who considered it a useful theory for understanding the facilitative process, with an underlying philosophical approach supporting lifelong learning and continuing professional development. ${ }^{19}$ Additional articles specifically referred to the benefits of a humanistic model in dental education, emphasizing the importance of teaching compassion, empathy, caring, and desire to give back of students' time, talents, and resources to their communities, the profession, and their schools. ${ }^{20-27}$ Empathy was discussed overall in 12 articles.

\section{Communication Skills and Emotional Intelligence}

Communication skills in dental education have been discussed by many authors. Carey et al. reported in their systematic review that evidence-based data on learning and assessment of communications skills in dentistry appeared to be of variable quality but indicated that most dental students were receptive to the use of simulated patient interactions as an educational tool. ${ }^{28}$ Emotional intelligence was specifically discussed in six articles, ${ }^{29-34}$ cultural competence in 27 articles, and humor in one article. ${ }^{35}$

\section{Ethics and Professionalism}

Professionalism in dental education was first reported in an article by Shefrin..$^{20}$ Morris and Sherlock studied the level of ethics among dental students from three dental schools in California and found that professional ethics declined steadily while cynicism increased, especially in the clinical years. ${ }^{36}$ Nash's study of a U.S. dental school curriculum in professional ethics concluded that, if the professional relationship of dentistry to society is to be sustained, each new generation of dentists must understand the nature of the profession and the ethical obligations of becoming a member of the profession. ${ }^{37}$ Chaves reported on the experience gained from the development of two new assessment tools, the Dental Ethical Sensitivity Test (DEST) and the Defining Issues Test (DIT), that have been used to measure students' achievement and enhance their skills in this area. ${ }^{38}$ Chaves's evidence found that small-group and casebased learning regarding ethical issues improved scores on these measures. Chaves mentioned that it is imperative that opportunities to recognize, analyze, and discuss ethical issues are integrated throughout dental curricula. 
Table 4. Articles on course descriptions or assessments related to humanities in dental education (DE), $n=85$

Article/First Author, Reference Number

Quick, reference 24

Graham BS, et al. Dental student academic integrity in U.S. dental schools: current status and recommendations for enhancement. J Dent Educ 2016;80(1):5-13.

Chen $\mathrm{V}$, et al. Measuring attitudes of dental students towards social accountability following dental education: qualitative findings. Med Teach 2016;38(6):599-606.

Tiller C. Dentistry and ethics by the road less Ethics and dental curriculum traveled. J Am Coll Dent 2011;78(3):11-3.

Bebeau MJ. The defining issues test and the four-component model: contributions to professional education. J Moral Educ 2002;31(3):271-95

Vivekananda-Schmidt $\mathrm{P}$, et al. A model of professional self-identity formation in student doctors and dentists: a mixed method study. BMC Med Educ 2015;15:83.

Poirier Tl, et al. Health professions ethics rubric: validation of reliability in an interprofessional health ethics course. J Dent Educ 2015;79(4):424-31.

Ilguy, reference 50

Gadbury-Amyot CC, et al. Self-assessment: a review of the literature and pedagogical strategies for its promotion in dental education. J Dent Hyg 2015;89(6):357-64.

Al-Ahmad, reference 17

Bissell V, Felix DH. The Francis report: implications for education and training of dental professionals. Dent Update 2015;42(3):215-8.

Munz, reference 33

Frost PM, et al. Constructing a royal dental hospital shield: a student technical exercise in the 1960s. Dent Historian 2014;59:31-2.

Donate-Bartfield E, et al. Teaching culturally sensitive care to dental students: a multidisciplinary approach. J Dent Educ 2014;78(3):454-64.

Henry RK, Molnar AL. Examination of social networking professionalism among dental and dental hygiene students. J Dent Educ 2013;77(11):1425-30.

Nguyen TM, et al. Developing professionalism in dentistry: a systematic review. MedEdPublish 17 May 2017:6. education (IPE)
Area of Humanities

Publication Type/Findings

Communication skills in DE

Professional ethics curricula in DE

Professionalism and social accountability of dental students

Ethics in professional DE

Professional self-identity (PSI) of dental students

Ethics in interprofessional

Ethical decision making in DE

Reflective learning

Theater-based learning

Ethics and professionalism

Emotional intelligence (EI) in DE

History of DE

Cultural sensitivity training

Professionalism and social networking

Evaluation of outcomes of professionalism-related programs
Study assessing new method for teaching communication; students found experience to be positive and participation was high

National survey study; schools reported various percentages of integrity policies; authors recommend schools add cheating case scenarios to ethics courses

Study of dental students regarding social accountability; concluded DE not producing graduates who endorse obligation to address oral health concerns of society

Description of ethics course leading to leadership opportunities in teaching ethics to dental students

Description of defining issues test and assessment methods validated for sensitivity, reasoning, role concept, and ethical implementation

Study of students' PSI; results provide model of experiences and mechanisms affecting PSI development

Study to validate and assess reliability of ethics rubric in IPE ethics course

Study comparing $4^{\text {th }}$ year dental students' scores pre- and post-ethics course; scores were significantly higher after course

Review relating theory of self-assessment to $\mathrm{DE}$ and describing pedagogical strategies to implement self-assessment in two dental schools

Cross-sectional student survey comparing theater-based to conventional oral surgery training

Essay on importance of education based on ethical principles highlighted in Francis report

Categorization of El-related infractions with use of emotional and social competence inventory

Historical article

Description of multidisciplinary course in culturally sensitive care for dental students

Study of dental and dental hygiene students' social media use; authors proposed use of media in professionalism training

Systematic review based on Kirkpatrick's hierarchy showed mostly low levels of outcomes 


\section{Table 4. Articles on course descriptions or assessments related to humanities in dental education (DE), $\mathrm{n}=85$ (continued)}

Article/First Author, Reference Number

Gorkey S, et al. Towards a specific approach Ethics in DE

to education in dental ethics: a proposal

for organizing the topics of biomedical

ethics for dental education. J Med Ethics

2012;38(1):60-3.

Flaitz CM, et al. The journey beyond silos: teaching and learning interprofessional ethics at UTHealth. Tex Dent J 2011; 128(8):716-26.

Erratt, reference 48

Chambers DW. Developing a self-scoring comprehensive instrument to measure Rest's four-component model of moral behavior: the moral skills inventory. J Dent Educ 2011;75(1):23-35.

Yusof ZY, et al. Malaysian dental graduates' competence in holistic care: what do graduates and employers think? J Dent Educ 2010;74(12):1380-7.

Brondani MA, Rossoff LP. The "hot seat" experience: a multifaceted approach to the teaching of ethics in a dental curriculum. J Dent Educ 2010;74(11):1220-9.

Schwartz B. An innovative approach to teaching ethics and professionalism. J Can Dent Assoc 2009;75(5):338-40.

Lantz MS. Dental students persuade the Michigan Dental Association to strengthen its codes of ethics: do actions speak louder than words? J Am Coll Dent 2008;75(2):22-6.

McCabe DL, et al. Values and ethical decision making among professional school students: a study of dental and medical students. Prof Ethics 1992;1(3/4):117-36.

Patthoff DE. The need for dental ethicists and Ethics in DE the promise of universal patient acceptance. Jent Educ 2007;71(2):222-6.

Christen, reference 52

Garetto LP, Senour WE. Using an ethics across the curriculum strategy in dental education. J Am Coll Dent 2006;73(4):33-7.

Gadbury-Amyot CC, et al. Using a multifaceted approach including communitybased service-learning to enrich formal ethics instruction in a dental school setting. J Dent Educ 2006;70(6):652-61.

Salveson C. Interdisciplinary ethics course for nursing, dental, and medical students. Commun Nurs Res 2005:38:193.

Gillet D, et al. Is there a link among writing ability, drawing aptitude, and manual skills of dental students? Eur J Dent Educ 2002;6(2):69-73.

Zarkowski, reference 41 education

Ethics in DE

Ethics in DE

Ethics in DE

Ethics in DE education

Ethics in DE
Ethics in interprofessional

Ethics and moral behavior

Holistic care and DE

Codes of ethics and DE

Ethical decision making in dental Survey of dental and medical students using and medical education

Art and ethics in DE

Ethics and professionalism in DE

Ethics in interprofessional

Writing and drawing skills in relation to dental skills
Publication Type/Findings

Description of organization of ethics

education in a Turkish dental school

Description of development of interprofessional ethics course

Qualitative study of dental, medical, and pre-dental students and faculty on barriers to ethics education

Development and validation of moral skills inventory used in DE to measure Rest's four component model of moral behavior

Study evaluating 19 competencies of dental graduates and employers in holistic care in a Malaysian university

Description of three pedagogies to teach ethics: "hot seat" experience, small-group presentations of ethical cases, and student reflections from SP encounters

Description of innovative course teaching ethics and professionalism in a North American dental school

Case study of how four groups (including $1^{\text {st }}$ year dental students) viewed proposed language in professional ethics Rokeach terminal values scale, demographic data, and responses to five ethical decision cases

Response to article on professionalism in $\mathrm{DE}$; endorsed need for dental ethicists

Essay on history and ethical lessons from a sculpture at a Spanish university

Description of ethics and professionalism instruction in a North American university

Study of dental and dental hygiene students' attitudes pre and post 7-week ethics course; significant differences found from beginning to end of course

Study of dental, nursing, and medical students

Study testing relation between dental students' manual aptitude in writing/drawing tests and practical assessment results

Description of four-year curriculum of ethics courses at a North American dental school 
Table 4. Articles on course descriptions or assessments related to humanities in dental education (DE), $\mathrm{n=85}$ (continued)

Article/First Author, Reference Number

Crutchfield $\mathrm{P}$, et al. The limits of deontology in dental ethics education. Int J Ethics Educ 2016;1(2):183-200.

Bebeau MJ. Does this integrated law and ethics curriculum promote ethical thinking? J Am Coll Dent 2001;68(2):27-30.

Ozar, reference 39

Nash, reference 37

Díaz-Narváez VP, et al. Empathy and gender in dental students in Latin America: an exploratory and cross-sectional study. Health 2015;7(11):1527.

Nolan PW, Smith J. Ethical awareness among first-year medical, dental, and nursing students. Int J Nurs Stud 1995;32(5):506-17.

Pollack BR. Teaching law, ethics, and risk management at the School of Dental Medicine State University of New York at Stony Brook. J Law Ethics Dent 1989;2(1):32-49.

Feldman CA, et al. Teaching ethics, jurisprudence, and risk management at the New Jersey Dental School. J Law Ethics Dent 1989;2(2):101-6.

Hasegawa TK Jr. Professional ethics instruction at Baylor College of Dentistry. J Law Ethics Dent 1988;1(4):230-2.

Clarke JH, et al. The content of a dental history course: what should be taught? Bull Hist Dent 1988;36(2):134-9.

Odom JG. Teaching dental students to solve ethical problems. Dentistry (Chicago) 1987;7(2):16-8.

Bebeau MJ, et al. Measuring dental students' ethical sensitivity. J Dent Educ 1985;49(4):225-35.

Bebeau MJ. Teaching ethics in dentistry. J Dent Educ 1985;49(4):236-43.

Odom JG. Parameters and goals for teaching Ethics in DE ethics. Ohio Dent J 1984;58(3):36-9.

Nordstrom WR, et al. How a dental museum, built and staffed by dental students, helps generate interest in dental history. Bull Hist Dent 1983;31(1):18-22.

Bebeau MJ. Professional responsibility curriculum report: American College fellows serve as expert assessors. J Am Coll Dent 1983;50(2):20-3.

Shefrin, reference 20

Miller SL. Self-instruction as a means for teaching the history of dentistry. Bull Hist Dent 1973;21(2):95-100.

Ethics in DE

Ethics in DE education in DE

Ethics in DE
Area of Humanities

Publication Type/Findings

Dental ethics education

Ethics and professionalism in DE

Empathy in DE

Ethics in interprofessional

Ethics, law, and risk management Description of course in law, ethics, and risk

Ethics and law in DE

Ethics and law in DE

History in DE

Ethics and cognitive

development in $\mathrm{DE}$

Ethical sensitivity and moral reasoning in $\mathrm{DE}$

History in DE

Professionalism in DE

Professionalism and ethics in DE

History in DE
Survey found adherence to duties compared to caring had weaker association with students' ethical judgments and behavior

Analysis of combined ethics and law fouryear curriculum

History of ethics education in dental and dental hygiene programs from 1980s

Description of professionalism course across predoctoral curriculum

Cross-sectional study of dental students' empathy levels measured by Jefferson scale of empathy; variable results for both genders

Study of ethical views and knowledge of medical, dental, and nursing students in response to vignettes management taught since 1977 and revised in 1988

Description of teaching ethics, jurisprudence, and risk management to dental students and faculty

Description of instruction in professional ethics for dental students

Description of a dental history course

Essay

Study of dental students found high internal consistency compared to previous efforts to study sensitivity

Description of course to help dental students identify and resolve ethical problems

Description of parameters and goals for teaching ethics to dental students

Description of a dental museum built and staffed by dental students and its association with teaching dental history

Report on teaching ethics with American College fellows serving as expert assessors

Description of role-playing method to teach professionalism and ethics

Description of self-instruction as method for teaching history of dentistry 
Table 4. Articles on course descriptions or assessments related to humanities in dental education (DE), $\mathrm{n}=85$ (continued)

Article/First Author, Reference Number

Mock JI, et al. New approach to drawing in dental anatomy. J Dent Educ 1968;32(3):279-82 .

Brett-MacLean, reference 15

Wener ME, et al. Developing new dental communication skills assessment tools by including patients and other stakeholders. J Dent Educ 2011;75(12):1527-41.

Zahra, reference 22

Brondani MA. Students' reflective learning in a community service-learning dental module. J Dent Educ 2010;74(6):628-36.

Oakley, reference 60

Victoroff, reference 30

Brett-MacLean PJ, et al. Film as a means to introduce narrative reflective practice in medicine and dentistry: a beginning story presented in three parts. Reflect Pract 2010;11(4):499.

Tsang KL, Walsh LJ. Oral health students' perceptions of clinical reflective learning: relevance to their development as evolving professionals. Eur J Dent Educ 2010;14(2):99.

Tricio J, et al. Dental students' reflective habits: is there a relation with their academic achievements? Eur J Dent Educ 2015;19(2):113

Novak KF, et al. Students' perceived importance of diversity exposure and training in dental education. J Dent Educ 2004;68(3):355-60.

Donate-Bartfield E, Lausten L. Why practice culturally sensitive care? Integrating ethics and behavioral science. J Dent Educ 2002;66(9):1006-11.

Gregorczyk SM, Bailit HL. Assessing the cultural competence of dental students and residents. J Dent Educ 2008;72(10):1122-7.

Rowland ML, et al. A snapshot of cultural competence in U.S. dental schools. J Dent Educ 2006;70(9):982-90.

Saleh L, et al. An assessment of crosscultural education in U.S. dental schools. J Dent Educ 2006;70(6):610-23.

Forsyth CJ, et al. Teaching cultural competence in dental education: a systematic review and exploration of implications for indigenous populations in Australia. J Dent Educ 2017;81(8):956-68.
Area of Humanities

Art (drawing) in DE

Art (theater) in DE

Holistic dentistry and

communication skills education

Art and humanities in DE

Reflective learning

Social media in DE

Emotional intelligence (EI) in DE

Narrative reflective learning

Reflective learning

Reflective learning

Diversity issues

Cultural competence

Cultural competence

Cultural competence

Cultural competence

Cultural competence
Publication Type/Findings

Description of drawing as teaching approach in dental anatomy

Description of teaching professionalism in DE based on ForumTheater created by Brazilian director Augusto Boal

Study of dental students and assessment development

Description of pilot 6-session course integrating arts and humanities in DE

Study analyzing dental students' reflections before, during, and after community learning; results showed positive impact on attitudes about service and community members

Call for research on professionalism and social media in DE

Study of relationship between dental students' El and clinical performance

Pilot test of film-based module with medical and dental students; feedback supported its use

Description of clinical reflective learning course in curriculum of an Australian oral health program; students perceived program positively

Cross-sectional study of reflection habits of dental students and $\mathrm{PhD}$ trainees

Survey of dental students supported importance of diversity exposure and training in dental school

Description of teaching method with clinical vignettes; proposal to integrate ethics and behavioral science

Literature review of cultural competence education in health professions and instruments to assess student knowledge and clinical performance

National (U.S.) survey of cultural competence courses; found little standardization and variety of methods

National (U.S.) survey of cross-cultural education; found variety of teaching and evaluation methods

Literature review of cultural competence interventions in Australian dental curricula 
Table 4. Articles on course descriptions or assessments related to humanities in dental education (DE), $\mathrm{n=85}$ (continued)

Article/First Author, Reference Number

Ratzmann A, et al. Early patient contact

in undergraduate dental education in

Germany: the Greifswald model. Eur J Dent

Educ 2007;11:93-8.

Gorter RC, Eijkman AJ. Communications skills training courses in dental education. Eur J Dent Educ 1997;1:143-7.

Sherman JJ, Cramer A. Measurement of changes in empathy during dental school. J Dent Educ 2005;69(3):338-45.

Croft $\mathrm{P}$, et al. Evaluation by dental students of a communication skills course using professional role players in a UK school of dentistry. Eur J Dent Educ 2005;9:2-9.

Hannah A, et al. A communication skills course for undergraduate dental students. J Dent Educ 2004;68(9):970-7.

Lanning SK, et al. Communication skills instruction utilizing interdisciplinary peer teachers: program development and student perceptions. J Dent Educ 2008;72(2):172-82.

Teplitsky PE. Perceptions of Canadian dental Academic integrity faculty and students about appropriate penalties for academic dishonesty. J Dent Educ 2002;66(4):485-506.

Theaker ED, et al. Development and preliminary evaluation of an instrument designed to assess dental students' communication skills. Br Dent J 2000; 188(1):40-4.

Bailit HL, et al. The origins and design of the dental pipeline program. J Dent Educ 2005;69(2):232-8.

Leviton LC. Foreword: evaluating the dental pipeline program. J Dent Educ 2009;73(2 Suppl):S5-7.

Brondani MA, et al. An evolving community-based dental course on professionalism and community service. J Dent Educ 2008;72(10):1160-8.

Cannick GF, et al. Use of the OSCE to evaluate brief communications skills training for dental students. J Dent Educ 2007;71(11):1203-9.

Orsini, reference 34

Aleksejuniene J, et al. Self-perceptions of cultural competence among dental students and recent graduates. J Dent Educ 2014;78(3):389-400.

Victoroff KZ, et al. Dental students' reflections on their experiences with a diverse patient population. J Dent Educ 2013;77(8):982-9.

Whitehead AW, Novak KF. A model for assessing the ethical environment in academic dentistry. J Dent Educ 2003;67(10):1113-21.
Area of Humanities

Communication skills in DE

Communication skills in DE

Empathy in DE

Communication skills in DE using professional role players

Communication skills in DE

Communication skills in DE

Communication skills in DE

Cultural competence; minorities in $\mathrm{DE}$

Cultural competence; minorities in DE

Professionalism and community practice in DE

Communication skills in DE

Communication skills and emotional intelligence (EI) in DE

Cultural competence in DE

Cultural competence

Ethics in DE
Publication Type/Findings

Description of new teaching concept in German DE based on interactions between community medicine and dentistry

Description of three courses at a Dutch dental school and results of students evaluation

Analysis of psychometric properties of measure of empathy applied to dental students

Study of student feedback on a role play methodology used in behavioral sciences teaching

Description of communication skills course with simulated patients, case-based scenarios, etc.

Cross-sectional study found students perceived a knowledge-observationsimulation-experience course to be worthwhile

Study comparing perceptions of dental faculty and students on academic dishonesty penalties; jurisprudence grid for appropriate disciplinary action presented

Study assessed inter-observer reliability of instrument to evaluate dental students' communication skills

Description of program aiming to reduce disparities in access to dental care; 15 U.S. dental schools participated

Evaluation of the dental pipeline program at 15 U.S. dental schools

Description of professionalism and community service course using communitybased dental education as experiential learning pedagogy

Study using OSCE to evaluate dental students' competence in interpersonal and tobacco cessation communication skills

Study of dental faculty definition of dentistpatient relationship skills informed by $\mathrm{El}$ concepts

Study assessed self-perceptions of cultural competence of students and recent graduates of a Canadian dental school

Qualitative study exploring students' reflections on their interactions with a diverse patient population in a clinical setting

Proposal to use Weber's institutional ethics audit model to assess dental schools' ethical environment 
Table 4. Articles on course descriptions or assessments related to humanities in dental education (DE), n=85 (continued)

Article/First Author, Reference Number

Raja S, et al. Teaching dental students about patient communication following an adverse event: a pilot educational module. J Dent Educ 2014;78(6):757-62.

Andrews KG, et al. Faculty and student perceptions of academic integrity at U.S. and Canadian dental schools. J Dent Educ 2007;71(8):1027-39.

Gonzalez MG, et al. Soft skills and dental education. Eur J Dent Educ 2013;17(2):73-82.
Area of Humanities

Communication skills in DE

Academic integrity in DE

Communication skills in DE
Publication Type/Findings

Description of six-hour pilot module to improve dental students' knowledge and confidence in communicating with patients about adverse events

U.S. and Canada survey; results showed significant differences between students' and faculty members' perceptions of academic integrity

Description of teaching and assessment of soft skills and model for soft skills teaching

Note: Those articles that appear in the references are referred to by last name of first author and reference number; those articles not in the references include full citation.

Ozar traced the development of ethics education in dentistry in the 1980s and later, highlighting the creation of PEDNET (the Professional Ethics in Dentistry Network), the appearance of several textbooks and journals featuring ethics columns, and the approval of formal guidelines for teaching ethics by the American Association of Dental Schools. ${ }^{39}$ Berk stated that promotion of ethical behavior in dental students was reflected in the emphasis on formal ethics teaching. ${ }^{40} \mathrm{He}$ noted, in 2001, that state-of-theart ethics education had moved from purely didactic to more interactional methodologies that promote student introspection and group problem-solving. Zarkowski and Graham described a predoctoral dental curriculum in which professional ethics were the basic core of humanities education, with a course on issues that students face for each stage of professional development. ${ }^{41}$ In addition, in an "Ethics Rounds" course, students presented a personal patient-based ethics case. Spike described the development of a medical humanities concentration, which motivated students to continue to pursue their humanistic interests in the third and fourth years of medical school. ${ }^{42}$ Welie emphasized that ethics education in dental schools can improve students' ability to reflect on ethical alternatives, but expressed his opinion that the most powerful influence for professional behavior comes from faculty role-modeling. ${ }^{43}$

Bertolami's exploration of "why our ethics curricula don't work" highlighted three specific weaknesses he identified in a typical ethics curriculum: 1) failure to recognize that more education is not the answer to everything, 2) ethics is boring, and 3) course content is qualitatively inadequate because it does not foster an introspective basis for true behavioral change. ${ }^{44} \mathrm{~A}$ fourth element-innovation —was directed to the third weakness and entailed implementing a "pre-curriculum" early in the curriculum to address the disconnect between knowledge and action. Sharp et al., underlining the importance of ethical engagement for dental students, stated that faculty who teach ethics must select a limited set of topics from the broad fields of professional ethics, bioethics, and the humanities. ${ }^{45}$

Nash stated that a variety of instructional methods are available and appropriate for teaching professional ethics, including lectures, readings, books, case scenarios, literature reviews, portfolios, role-plays, debates, general discussions, and cinema. ${ }^{46}$ Venues for instruction include classroom, websites, clinics, and the community, with methodologies utilized for engaging students being limited only by the creativity of the teacher. While some institutions had engaged professional philosophers, ethicists, or behavioral scientists to teach ethics to dental students, Nash noted his preference that dentists who are knowledgeable in the field of ethics teach these courses since instruction by a clinician enhances the relevance and validity of the subject matter to a student who is studying to become a dentist. Classroom and clinic protocols that promote basic concepts of morality must be established, Nash noted, to promote and reinforce the specific principles of ethics related to dentistry. Schwartz et al. reviewed and analyzed the importance of oaths, principles of ethics, and codes of professional conduct, considering oath-taking as an opportunity to instill in students important ethical obligations in dentistry, and they provided recommendations to make the content more meaningful and comprehensive. ${ }^{47}$ Schwartz and Bohay discussed the involvement of ethics and professionalism with interpersonal communications in dental education. ${ }^{18}$ 
Table 5. Articles with evidence of outcomes regarding use of humanities in dental education (DE) $(n=66)$

Article/First Author, Reference Number

Anyanwu, reference 11

Hillenburg, reference 71

Ford PJ, Hughes C. Academic integrity and plagiarism: perceptions and experience of staff and students in a school of dentistry. Eur J Dent Educ 2012;16(1):e180-6.

Bebeau MJ. Designing an outcomebased ethics curriculum for professional education: strategies and evidence of effectiveness. J Moral Educ 1993;22(3):313-26.

Escudier MP, et al. Student acceptability of high-stakes e-assessment in dental education: using privacy screen filters to control cheating. J Dent Educ 2014; 78(4):558-66.

Behar-Horenstein LS, et al. An assessment of Ethical decision making faculty and dental student decision-making in ethics. J Am Coll Dent 2014;81(4):44-50.

Al-Zain, reference 49

Tabei SZ, et al. Investigation of awareness of the students of Shiraz dental school concerning patients' rights and principles of ethics in dentistry. J Dent 2013;14(1):20-4.

Nelson, reference 25

Madhan, reference 35

Asokan S, et al. Attitudes of students and teachers on cheating behaviors: descriptive cross-sectional study at six dental colleges in India. J Dent Educ 2013;77(10):1379-83. You, reference 69

Schwartz, reference 18

Kurkowski MA. Off on the right foot. Northwest Dent 2012;91(4):41-2.
Area of Humanities

Publication Type/Contents

Background music in basic sciences and anatomy education

Cultural competence; lesbian, gay, bisexual, and transgender (LGBT) issues

Academic integrity

Ethics in DE

Academic integrity

Professional ethics in DE

Ethics in DE and patients' rights

Humanistic dentistry

Sense of humor $(\mathrm{SoH})$ among dental students

Academic integrity

Ethics and gender differences

Professionalism and empathy in DE

Professionalism
Study found medical and dental students who studied with background music had significantly higher scores on overall exams than those who did not

National (U.S.) survey found strategies for increasing LGBT content were curricular material on LGBT health issues and health disparities and having trained faculty teach LGBT content

Survey study to investigate perceptions and experience of plagiarism and assess usefulness of workshops; results showed enhanced understanding of plagiarism

Description of curriculum addressing ethical sensitivity, moral reasoning, moral motivation, and moral implementation

Study found privacy filters used in e-assessment improved dental students' confidence in fairness of computer-based assessments

Study compared dental student and faculty scores to national norms on Defining Issues Test 2, a measure of ethical decision making; results showed both groups tended to make decisions that promoted self-interest

Cross-sectional study of dental students and recent graduates found all considered professional ethics a very important prerequisite for dental practice

Study investigated dental students' awareness of and attitudes on patients' rights and principles of dental ethics; $71 \%$ were acquainted with patients' rights

Study showed feasibility of measuring dental students' humanistic qualities in $1^{\text {st }}$ year; these qualities were associated with clinical performance in $3^{\text {rd }}$ year

Study in which dental students completed Multidimensional Sense of Humor Scale and Depression Anxiety Stress Scales-21; further research was needed to correlate $\mathrm{SoH}$ and role of humor

Descriptive cross-sectional study compared attitudes of students and teachers on cheating behaviors in six dental colleges

Retrospective study found dental students' gender differences were not apparent for moral sensitivity, but were for one of the moral reasoning indices

Study on students' perceptions of integrating patients' voices into patient management course; students reported enhanced awareness of importance of empathy

Study of dental students using digital videos and one-on-one interviews 
Table 5. Articles with evidence of outcomes regarding use of humanities in dental education (DE) ( $\mathrm{n}=66)$ (continued)

Article/First Author, Reference Number

Koletsi-Kounari, reference 68

Al-Johany, reference 53

Brands WG, et al. The chasm between knowing and choosing the ethical course of action: a survey of dental students in the Netherlands. Int Dent J 2010;60(5):321-8.

Sharp HM, et al. What do dental students learn in an ethics course? An analysis of student-reported learning outcomes. J Dent Educ 2008;72(12):1450-7.

Rubin RW, et al. Exploring dental students' perceptions of cultural competence and social responsibility. J Dent Educ 2008;72(10):1114-21.

Kieser, reference 13

Hamel O, et al. Ethical reflection in dentistry: first steps at the Faculty of Dental Surgery of Toulouse. J Am Coll Dent 2006;73(3):36-9.

de Freitas SF, et al. Stages of moral development among Brazilian dental students. J Dent Educ 2006;70(3):296-306.

Sharp, reference 45

Krüger, reference 14

Acharya S. The ethical climate in academic dentistry in India: faculty and student perceptions. J Dent Educ 2005;69(6):671-80.

Schwartz B. A call for ethics committees in dental organizations and in dental education. J Am Coll Dent 2004;71(2):35-9.

Rubin RW. Developing cultural competence and social responsibility in preclinical dental students. J Dent Educ 2004;68(4):460-7.

Röding K. Human sciences in the first semester of the dental undergraduate course at the Karolinska Institute, Stockholm. Eur J Dent Educ 1999;3(3):106-8.

Chaves, reference 38

Bebeau MJ, Thoma SJ. The impact of a dental ethics curriculum on moral reasoning. J Dent Educ 1994;58(9):684-92.
Area of Humanities

Academic integrity

Writing and drawing skills of junior dental students

Ethics and law in DE

Ethics in DE

Cultural competence and social responsibility

Professional storytelling in denta anatomy education

Ethical reflection in DE

Moral reasoning in DE

Ethics in DE

Communication skills education with drama

Ethical educational environment

Ethics in DE

Cultural competence and social responsibility

Human sciences in DE

Ethics in DE

Ethics in DE
Publication Type/Contents

Study in which dental faculty and students selected penalties for hypothetical offenses; in results, faculty were harsher than students for same offenses

Study evaluated fine motor skills of dental students; results supported use of handwriting and basic drawing skills for initial evaluations

Survey found dental students' knowledge of health law increased from $1^{\text {st }}$ to $5^{\text {th }}$ years, but knowledge of ethics decreased

Study of $1^{\text {st }}$ year dental students ${ }^{\prime}$ perceptions of ethics and professionalism course; results showed increased awareness of professional role

Study found improvement in dental students' attitudes about community service and cultural competence after participation in non-dental community service

Study found evidence that storytelling nurtured reflective learning while students learned clinical anatomy

Survey of dental students, faculty, and department heads found most respondents favored teaching of ethics

Study found level of moral and ethical development of $1^{\text {st }}$ year dental students was low

Study collected $4^{\text {th }}$ year dental students reports of ethical issues during communitybased clinical experiences as foundation for designing practical dental ethics instruction

Study assessed medical and dental students' knowledge of communication skills pre- and post-intervention; found "forum theater" transferred knowledge of communication skills

Study assessed ethical climate in an Indian dental school; results showed need for better communication of ethical policies

Survey of Canadian faculties of dentistry regarding ethics resources

Study in which dental students participated in non-dental community service; intervention resulted in enhanced cultural understanding

Study assessing course introducing students to professionalism in patient-related health sciences; results showed students were positive about theme as a whole and specific seminars

Study using Dental Ethical Sensitivity Test and Defining Issues Test to assess development of ethical sensitivity reflective reasoning

Study of dental students using Defining Issues Test; in results, they benefitted from and valued ethics education 
Table 5. Articles with evidence of outcomes regarding use of humanities in dental education (DE) ( $n=66)$ (continued)

Article/First Author, Reference Number

Díaz-Narváez VP, et al. Levels of empathy among dental students in five Chilean universities. Health 2016;8(1):32.

Odom JG. The status of dental ethics instruction. J Dent Educ 1988;52(6):306-8.

Odom JG. Formal ethics instruction in dental education. J Dent Educ 1982;46(9):553-7.

Morris, reference 36

Miller SL, et al. Programmed course in dental ethics compared with two other methods of instruction. J Public Health Dent 1970;30(4):229-33

Strauss $R$, et al. Reflective learning in community-based dental education. J Dent Educ 2003;67(11):1234-42.

Mofidi M, et al. Dental students' reflections on their community-based experiences: the use of critical incidents. J Dent Educ 2003;67(5):515-23.

Beemsterboer PL, et al. Issues of academic integrity in U.S. dental schools. J Dent Educ 2000;64(12):833-8.

Wilhelm M, et al. Interprofessional ethics learning between schools of pharmacy and dental medicine. J Interprof Care 2014;28(5):478-80.

Bush H, Bissell V. The evaluation of an approach to reflective learning in the undergraduate dental curriculum. Eur J Dent Educ 2008;12(2):103-10.

Sharp HM, Kuthy RA. What do dental students learn in an ethics course? An analysis of student-reported learning outcomes. J Dent Educ 2008;72(12):1450-7.

Alrqiq HM, et al. Evaluating a cultural competence curriculum: changes in dental students' perceived awareness, knowledge, and skills. J Dent Educ 2015;79(9):1009-15.

Lyon, reference 26

Pilcher ES, et al. Development and assessment of a cultural competence curriculum. J Dent Educ 2008;72(9):1020-8.

Wagner J, et al. Dental student attitudes towards treating diverse patients: effects of a cross-cultural patient-instructor program. J Dent Educ 2008;72(10):1128-34.
Area of Humanities

Empathy in DE

Ethics in DE

Ethics in DE

Professional ethics and cynicism in $\mathrm{DE}$

Ethics in DE

Reflective learning

Reflective learning

Academic integrity

Interprofessional ethics education

Reflective learning

Professionalism in DE

Cultural competence

Humanistic environment in DE

Cultural competence

Cultural competence
Publication Type/Contents

Study validated Jefferson Scale of Physician Empathy (in Spanish) in Chile as adapted for dental students; results showed great variability of empathetic guidance

Survey found dental schools providing ethics instruction often confused law, jurisprudence, and avoidance of malpractice with ethics

Study found 3/4 of respondents had some commitment to teaching ethics but there was no agreement about content of instruction

Longitudinal study of professional socialization found that professional ethics declined and cynicism increased

Study of intervention used for ethics found it was not as effective as two other instruments available

Essay recommending reflection to increase impact of learning in community-based education

Study found dental students' reflections on critical incidents in community-based education facilitated professional development

National (U.S.) survey found incidents of academic dishonesty occurred in most dental schools

Study assessed dental and pharmacy students using Readiness for Interprofessional Learning Scale and for knowledge pre and post intervention; results found it increased knowledge of ethical decision making

Study of dental students' reflections found limited encouragement that they were acquiring skills for professional reflection

Study assessed $1^{\text {st }}$-year dental students perceptions of their primary learning outcomes from course in ethics and professionalism

Curriculum evaluation in U.S. dental school found it was effective in improving students' cultural competence knowledge and skills

Study of student and faculty perceptions of humanistic environment; respondents described humanism as manifest by attributes such as caring, understanding, respect, and compassion

Study of pre- and posttest scores found curriculum contributed to students' cultural knowledge and self-awareness

Study assessed cross-cultural patient-instructor (PI) program on dental students' attitudes about diversity; results found PIs were creative way to promote cross-cultural patient care 
Table 5. Articles with evidence of outcomes regarding use of humanities in dental education (DE) ( $n=66)$ (continued)

Article/First Author, Reference Number

Wagner JA, Redford-Badwal D. Dental students' beliefs about culture in patient care: self-reported knowledge and importance. J Dent Educ 2008;72(5):571-6.

Richards PS, Inglehart MR. An interdisciplinary approach to case-based teaching: does it create patient-centered and culturally sensitive providers? J Dent Educ 2006;70(3):284-91.

Broder HL, Janal M. Promoting interpersonal skills and cultural sensitivity among dental students. J Dent Educ 2006;70(4):409-16.

Wagner J, et al. A patient-instructor program to promote dental students' communication skills with diverse patients. J Dent Educ 2007;71(12):1554-60.

Pau, reference 32

Beattie A, et al. Does empathy change in first-year dental students? Eur J Dent Educ 2012;16(1):e111-6.

Muhney KA, Campbell PR. Allied dental and dental educators' perceptions of and reporting practices on academic dishonesty. J Dent Educ 2010;74(11):1214-9.

Bebeau MJ, Loupe MJ. Masculine and feminine personality attributes of dental students and their attitudes toward women's roles in society. J Dent Educ 1984;48(6):309-14.

Coombs JA. Factors associated with career choice among women dental students. J Dent Educ 1976;40(11):724-32.

Hottell TL, Hardigan PC. Improvement in the interpersonal communication skills of dental students. J Dent Educ 2005;69(2):281-4.

Gadbury-Amoyt CC, et al. Using a multifaceted approach including communitybased service-learning to enrich formal ethics instruction in a dental school setting. J Dent Educ 2006;70(6):652-61.

Hewlett ER, et al. Effect of school environment Cultural competence on dental students' perceptions of cultural competence curricula and preparedness to care for diverse populations. J Dent Educ 2007;71(6):810-8.

Haak R, et al. The effects of undergraduate education in communication skills: a randomized controlled clinical trial. Eur J Dent Educ 2008;12:213-318.

Aalboe JA, Schumacher MM. An instrument to measure dental students' communication skills with patients in six specific circumstances: an exploratory factor analysis. J Dent Educ 2016;80(1):58-64.

Area of Humanities

Cultural competence

Cultural competence

Cultural competence

Cultural competence

Empathy in DE

Academic integrity

Gender issues in DE

Gender issues in DE

Ethics in DE
Publication Type/Contents

Emotional intelligence (EI) in DE

Communication skills in DE

Communication skills in DE

Communication skills in DE
Survey of $2^{\text {nd }}-$ year dental students in a communication skills course at a U.S. dental school found instrument was useful in assessing development of communication skills

Study of effect of course to increase knowledge of other cultures; results showed dental students needed cross-cultural training and found it important

Study found interdisciplinary, case-based teaching increased students' appreciation of complexity of patient care and of a patientcentered, culturally sensitive approach to diagnosis

Study of effects of two clinical communications sessions; results showed statistically significant increases in communication skills for each session

Study of patient-instructor program to teach and assess dental students' communication skills; results pointed to curriculum changes to improve skills

Multinational survey found inverse relationship between $\mathrm{El}$ and stress in diverse contexts

Study used modified Jefferson Scale of Physician Empathy to assess cognitive-affective aspect of students' empathy

Study found majority of educators had observed cheating and perceived disparities between students and educators and among cultural groups in defining academic dishonesty

Study of dental students with academic psychologists found successful professionals had similar personality traits regardless of gender

Study found male and female students differed significantly in time of career decision, factors influencing decision, previous dental-related work experience, and parents' work and educational history

Study evaluated students pre- and postpsychology course; results showed significantly higher interpersonal skills after course

Study assessed student attitudes pre- and postcommunity service-learning; results showed statistically significant differences in attitudes and by gender regarding impact on career choice

Study used results from 2013 ADEA survey of dental seniors to aid in development of cultural competence curricula and directions for future study

Randomized trial of dental students found significantly greater improvement of communication skills in test group than control group

(continued) 
Table 5. Articles with evidence of outcomes regarding use of humanities in dental education (DE) ( $\mathrm{n}=66)$ (continued)

Article/First Author, Reference Number

da Graça Kfouri, reference 70

Lancaster DM, et al. Dental students' class attitudes: a four-year study. J Am Coll Dent 1989;56:30-5.

Chalkley Y. A survey of minority student recruitment and retention efforts in dental schools. J Dent Educ 1995;59(6):645-8.

Bedi R, Gilthorpe MS. Social background of minority ethnic applicants to medicine and dentistry. Br Dent J 2000;189:152-4.

Yarascavitch C, et al. Changes in dental student empathy during training. J Dent Educ 2009;73(4):509-17.

Field J, et al. Teaching and assessment of professional attitudes in UK dental schools: commentary. Eur J Dent Educ 2010;14:133-5

Hannah, reference 31
Area of Humanities

Publication Type/Contents

Gender issues and empathy in DE Study of students in a Brazilian dental school found men wanted more technical learning and instruction in business administration and women were unhappy with personal relationships

Academic integrity

Minority recruitment in DE

Survey of class attitudes in all four years at a U.S. dental school found while many attitudes remained stable, some had significant changes

Survey of overall recruitment and retention of minority students in dental schools

Minority recruitment in DE Empathy in DE

Professionalism in DE

Retrospective analysis of national (UK) admissions data found significant inter-ethnic differences in social background of students entering medicine and dentistry

Study in Canadian dental schools using instrument that separately evaluated emotive and cognitive types of empathy

Survey of UK dental schools found all responding schools recognized importance of professionalism and reported it was taught and assessed in their curricula

Emotional intelligence in DE
Study evaluated dental students in New Zealand with Social Skills Inventory; results found women had higher global social skills and were more emotionally expressive and sensitive than men

Note: Those articles that appear in the references are referred to by last name of first author and reference number; those articles not in the references include full citation.

In their study, students accepted new educational methodologies integrating patients' voices into a management course positively; the experience raised their awareness of empathy.

Tyagi et al. pointed out the significance of ethics and professionalism in dental education and concluded that understanding the role of social, economic, environmental, and other factors in determining health status is critical if greater equity in dental education and care is to be achieved. ${ }^{5}$ Erratt discussed the importance of pre-health programs in the ethical development of future doctors using multiple strategies, including humanities. ${ }^{48}$ Al-Zain et al. noted that generally, in Saudi Arabian dental schools, religious teachings and spirituality were considered as one of the top motives for practicing professional ethics in dentistry. ${ }^{49}$ In that instruction, students appreciated professional ethics as a highly significant factor for their success in dental practice and their position in society. Ilguy suggested that dental curricula should increase students' awareness of ethical issues..$^{50}$ Finally, Masella stated that "institutional consensus on professionalism should be developed among faculty, administration, and students through passionate advocacy and careful analysis of dentistry's moral convictions." ${ }^{51}$

\section{Art}

Christen and Christen, in their article about ethics, observed the equestrian sculpture "The Torch Bearers" at the University of Madrid Dental School and concluded that the torch of learning and thinking is passed on. ${ }^{52}$ They stated that computer technology used exclusively as a mode of teaching and learning cannot become a substitute for interactive methods, which emphasize human-to-human interaction. Connections between art and dental education were also discussed by Al-Johany ${ }^{53}$ and Anyanwu. ${ }^{11}$

\section{Cultural Competence}

Finally, cultural competence was discussed in 27 articles. Quick extensively discussed the need for integration of humanities in dental education, through collegial conversations, reflective practice, 


\section{Table 6. Articles about attitudes regarding use of humanities in dental education (DE) $(n=40)$}

Article/First Author, Reference Number

Lew S. Are dentists avoiding their metaphorical vegetables? Br Dent 2016;221(9):536.

Patrick AC. A review of teaching ethics in the dental curriculum: challenges and future developments. Eur J Dent Educ 2017;21(4):e114-8.

Feng, reference 72

Quick, reference 23

Woodmansey KF, et al. International volunteer programs for dental students: results of 2009 and 2016 surveys of U.S. dental schools. J Dent Educ 2017;81(2):135-9.

Berge ME, et al. A critical appraisal of holistic teaching and its effects on dental student learning at University of Bergen, Norway. J Dent Educ 2013;77(5):612-20.

Alcota M, et al. Development of ethical practices and social responsibility in dental education at the University of Chile: student and faculty perceptions. Eur J Dent Educ 2013;17(1):e70-6.

Lantz MS, et al. The status of ethics teaching Ethics in DE and learning in U.S. dental schools. J Dent Educ 2011;75(10):1295-309.

Carreon D, et al. Altruism in dental students. J Health Care Poor Underserved 2011;22(1):56-70.

Brands WG, et al. Professional ethics and cynicism amongst Dutch dental students. Eur J Dent Educ 2011;15(4):205-9.

Markman S. Academic integrity in dental school: a call to action. J Am Coll Dent 2009; $76(4): 4$.

Ozar DT. The future of dental ethics: Part 1. What to hope for and the challenge of getting there. J Am Coll Dent 2008;75(1):25-9.

Hutchins B, Cobb S. When will we be ready for academic integrity? J Dent Educ 2008;72(3):359-63.

Koerber A, et al. Enhancing ethical behavior: views of students, administrators, and faculty. J Dent Educ 2005;69(2):213-24.

Yoshida T, et al. How do U.S. and Canadian dental schools teach interpersonal communication skills? J Dent Educ 2002;66(11):1281-8.

Sharp H, Stefanac SJ. Ethics education in dental school: continuing the conversation. J Dent Educ 2004;68(8):801-2.

Area of Humanities

Publication Type/Contents

Communication skills, ethics, and professionalism in DE

Ethics in DE

Cultural competence, LGBT issues

Humanistic environment and DE

Cultural competence,

humanitarianism

Holistic teaching in DE

Ethics and professionalism

Altruism

Ethics and cynicism

Academic integrity

Ethics in DE

Professionalism and ethics in DE

Ethics in DE

Communication skills in DE

Ethics in DE
Letter on "soft skills" such as ethics, communication, and professionalism

Study found, despite improved teaching of ethics, further study is needed to include patient views and develop a theoretically robust approach to self-reflection

Study concluded with authors' urging dental school administrators to explore degree to which their programs teach respectful and caring behavior toward LGBT students and patients

Study of dental students found greater effort should be directed toward creating a more humanistic environment in dental schools

Study of U.S. dental schools found increased number of schools providing international experiences for their students and established baseline data to assess future trends

Literature review; quantitative results did not support hypothesis that holism improved students' satisfaction with teaching

Study of dental students and faculty found that current dental school curriculum needed to be reviewed

National (U.S.) study noted 4 needs: integrate ethics across curricula; assess competence; expand faculty development; pay more attention to instruction method

Study found student characteristics were most significant predictors and students with altruistic personalities attended schools where social context was more accepting and respectful of diversity

Study found graduating students were significantly less cynical than freshmen, but $2 / 3$ were still cynical about dental profession

Commentary

Presentation of 6 ethical skills every dentist should possess; proposed strengthening dental ethics curricula and development of ethics teachers

Description of professionalism program and ways to involve faculty in development of professionalism at their institutions

Six essays on professional ethics instruction by students, administrators, and faculty at one dental school

Survey of North American dental schools on their communication skill training

Comment on article on ethics in DE 
Table 6. Articles about attitudes regarding use of humanities in dental education (DE) $(n=40)$ (continued)

Article/First Author, Reference Number

Bertolami, reference 44

Welie, reference 43

Hobdell M, et al. Ethics, equity, and global responsibilities in oral health and disease. Eur J Dent Educ 2002;6(Suppl 3):167-78.

Odom JG, et al. Revisiting the status of dental ethics instruction. J Dent Educ 2000;64(11):772-4.

Odom JG. Academic and clinical ramifications of integrity and cheating. J Dent Educ 1997;61(8):681-5.

Beemsterboer PL. Academic integrity: what kind of students are we getting, and how do we handle them once we get them? J Dent Educ 1997;61(8):686-8.

Hershey HG. Professors and professionals: higher education's role in developing ethical dentists. J Am Coll Dent 1994;61(2):29-33.

Blechner BB, et al. The Jay Healey technique: teaching law and ethics to medical and dental students. Am J Law Med 1994;20(4):439-55.

Ozar DT. The ethical ramifications of cheating. J Dent Educ 1991;55(4):276-81.

Isaac $\mathrm{C}$, et al. Impact of reflective writing assignments on dental students' views of cultural competence and diversity. J Dent Educ 2015;79(3):312-21.

Babar MG, et al. An assessment of dental students' empathy levels in Malaysia. Int J Med Educ 2013;4:223.

Holtzman JS, Seirawan H. Impact of community-based oral health experiences on dental students' attitudes towards caring for the underserved. J Dent Educ 2009;73(3):303-10.

Anderson, reference 73

Formicola A, et al. The dental pipeline program's impact on access disparities and student diversity. J Am Dent Assoc 2009;140:346-5.

Warman E, et al. Dental students' attitudes toward cheating. J Dent Educ 1994;58(6):402-5.

Turner SP, Beemsterboer PL. Enhancing academic integrity: formulating effective honor codes. J Dent Educ 2003;67(10):1122-9.

McCreary CP, Gershen JA. Changes in personality among male and female dental graduates. J Dent Educ 1982;46(5):279-83.
Area of Humanities

Publication Type/Contents

Ethics in DE

Ethics in DE

Ethics and global education

Ethics, academic integrity in DE

Academic integrity

Academic integrity

Ethics in DE

Ethics and law in DE

Academic integrity

Cultural competence and reflective writing

Empathy in DE

Cultural competence

LBGT issues

Minorities in DE

Academic integrity

Academic integrity

Gender issues in DE
Identification of weaknesses in a typical ethics curriculum

Examination of psychosocial, pedagogical, metaethical, and moral implications of faculty roles

Recommendations and goals regarding ethics and global responsibilities in oral health

Survey of faculty responsible for academic integrity found continuing emphasis on dental ethics instruction

Proposal of alternative to traditional solutions to academic cheating, with implications for dental students' professionalism

Presentation of data on students' values and behaviors before dental school and discussion of faculty role in prevention and treatment of academic dishonesty

Essay arguing dental educators should aim to produce practitioners who continue to develop as ethical professionals through ongoing learning, experience, and reflection

Presentation of legal and ethical aspects of medical and dental curricula

Commentary

Study examined linguistic differences in dental students' reflective writing pre and post interviewing an individual culturally different from themselves

Study used Jefferson Scale of Empathy-Health Care Provider Student version with dental students; construct validity and internal consistency were confirmed

Survey of dental students before, during, and after oral health promotion and preventive dental care program for underserved elementary school children

Study assessing dental student leaders' perceptions of educational efforts and culture concerning LGBT topics

Description of program for 15 schools; all schools developed courses in cultural competence and public health and increased enrollment of underrepresented minority students

Survey of students at a U.S. dental school investigated attitudes about specific cheating behaviors

Discussion of elements of an effective and valid honor code and its role in enhancing dental school environment

Study assessed personality traits of male and female students and graduates with Comrey personality scales 
Table 6. Articles about attitudes regarding use of humanities in dental education (DE) (n=40) (continued)

Article/First Author, Reference Number

Al-Dwairi ZN, Al-Waheidi EM. Cheating behaviors of dental students. J Dent Educ 2004;68(11):1192-5.

Hayes-Bautista DE, et al. The rise and fall of the Latino dentist supply in California: implications for dental education. J Dent Educ 2007;71(2):227-34.

Abu Kasim NH, et al. Pairing as an instructional strategy to promote soft skills amongst clinical dental students, Eur J Dent Educ 2014;18(1):51.

Raja S, et al. Patients' perceptions of dehumanization of patients in dental school settings: implications for clinic management and curriculum planning. J Dent Educ 2015;79(10):1201-7.

Seymour B, et al. Patient-centered communication: exploring the dentist's role in the era of e-patients and health 2.0. J Dent Educ 2016;80(6):697-704.

Broder HL, et al. Communication skills in dental students: new data regarding retention and generalization of training effects. J Dent Educ 2015;79(8):940-8.

Díaz-Narváez VP, et al. Empathy levels of dental students of Central America and the Caribbean. Health 2015;7(12):1678.

Díaz-Narváez VP, et al. Empathy levels of dentistry students in Peru and Argentina. Health 2015;7(10):1268.
Area of Humanities

Academic integrity

Cultural competence, minorities in DE

Communication skills in DE Empathy in DE

Communication skills in DE

Communication skills

Empathy in DE

Empathy in DE
Publication Type/Contents

Study of dental students in Jordan found the importance of issue of cheating and how it was evaluated

Demographic survey to identify Latino dentists in California showed a significant decline from 1983 to 2000

Study identified development of soft skills when dental students were paired in clinical training; negative and positive behaviors were reported

Qualitative study of dental students; participants made suggestions for how oral health professionals can successfully engage patients in treatment

Study in which students expressed high interest in learning how to harness modern health communications in clinical care

Study found a clinical communications program improved students' data-gathering and interpersonal skills; skills were maintained through completion of D4 year

Study compared students of 9 faculties using Jefferson Scale of Physicians Empathy; found variability of empathy

Study compared students of 2 faculties on levels of empathy; found empathy was able to differentiate populations

Note: Those articles that appear in the references are referred to by last name of first author and reference number; those articles not in the references include full citation.

and formal ethics education in predoctoral dental curricula. ${ }^{23,24}$

Reviewing the relevant literature of almost the past 50 years on humanities in predoctoral dental education, we found that few authors systematically investigated whether humanities in dental curricula had observable impact on the attitudes, competence, and practice of future dentists. In spite of this lack of evidence of long-term impact, many dental educators claimed that the introduction of humanities in predoctoral dental education undoubtedly adds more emphasis on values, ethics, and culture of caring. Conducting research into the effects of any curricular intervention is complicated by a number of methodological obstacles. It is particularly difficult to demonstrate outcomes of a learning activity in the multifaceted areas of the humanities because of the vast plurality of possible confounders. ${ }^{10}$ While there is a belief among some dental educators that humanities could lead to the development of imagination, creativity, self-awareness, and empathy for the patients, the answer to the question of whether humanistic education guarantees that students will eventually be exceptional professionals is not yet clear from the literature. Furthermore, clear guidelines for the use of the humanities in future dental curricula have not been identified. ${ }^{21}$

\section{Discussion}

From our perspective, predoctoral dental curricula are overwhelmed by biomedical sciences and innovative methods of teaching. The foundation of dental education includes a guiding ethos; still, there is a limited presence of humanities, leading to a potential of losing compassion in the practice of dentistry, due to lack of encouragement and of time for reflection by dental students. ${ }^{54,55}$ Humanities, 
by providing essential philosophic, developmental, and pedagogical concepts that are necessary to teach students to be interested in the patient as a whole rather than the symptom alone, are very important for the high-quality education of future dentists. ${ }^{1,56}$ Trying to define specifically what humanities should accomplish in a dental curriculum, one could come to a conclusion that humanities provide insight into human conditions, illness and suffering, and perception of oneself, as well as into professionalism and responsibilities to self and others, colleagues, and patients. ${ }^{1}$ In other words, the use of humanities in predoctoral dental education aims to educate dental students globally, rather than merely teaching them clinical skills. ${ }^{57}$

We found that topics such as mindfulness in dental education are scarcely discussed ${ }^{58}$ while the subject of narrative dentistry has just recently started to be examined as a means to enhance dental students' professionalism and empathy. ${ }^{59}$ The relationship between professionalism training in dental education and social media has also been discussed. ${ }^{60-63}$ Furthermore, Zahra and Dunton discussed the need for evaluation of art interventions in clinical education and presented a pilot project that aims to integrate humanities, art, craft, and science in dental education. ${ }^{22}$

Recently, Lyon et al.'s study assessed the humanisitic environment that forms the basis of their dental school. ${ }^{26}$ These authors recognized "that more varied, robust methods were needed to assess institutional alignment with stated goals for a humanistic learning environment." Patrick expressed the concern that, in dental education, the concepts of professionalism and ethics have been used interchangeably. ${ }^{64} \mathrm{In}$ addition, the educational environment is important for both faculty and students, ${ }^{65}$ and Murdoch-Kinch et al. found that a humanistic environment was said to be important by $97 \%$ of faculty members, $95 \%$ of staff members, and $94 \%$ of students in their dental school. ${ }^{66}$ We found numerous publications $(n=21)$ related to academic integrity, among them Karimbux ${ }^{67}$ and Koletsi-Kounari. ${ }^{68}$ Finally, gender differences in ethics and professionalism of dental students were discussed by You and Bebeau ${ }^{69}$ and da Graça Kfouri et al., ${ }^{70}$ while LBGT issues in dental education were researched in three studies..$^{71-73}$ These and other articles we examined reinforced Osler's caution to physicians to "care more particularly for the individual patient than for the special features of the disease." $" 74$

Limitations of our research were that the screening of articles (in both the primary and secondary review) was performed by two of the authors
(K.M. and A.I.M.), but the categorization of resulting articles was performed by one of the authors (K.M.). Another limitation is that only publications in the English literature were included in our review.

\section{Conclusion}

Dentists must be educated to see, hear, and understand their patients. Therefore, there is always a need for education in the humanities in dental education. Future dentists need to be educated appropriately to develop abilities not only to interpret data through analytical and synthetic reasoning, but also to carefully observe the patient and hear his or her language. Humanities can help future dental professionals develop empathy for their patients, constructing personal and professional values based on sound foundations. Our review found that limited studies provide evidence of the impact of humanities on dentists and their competence to treat patients holistically, leaving many questions that need to be further studied.

\section{Disclosure}

The authors reported no conflicts of interest.

\section{REFERENCES}

1. Batistatou A, Doulis EA, Tiniakos D, et al. The introduction of medical humanities in the undergraduate curriculum of Greek medical schools: challenge and necessity. Hippokratia 2010;14(4):241-3.

2. Brody H. Defining the medical humanities: three conceptions and three narratives. J Med Humanities 2011;32(1):1-7.

3. Hunt D. Medical humanities. In: Dent J, Harden R, Hunt D. A practical guide for medical teachers. 5 th ed. Amsterdam: Elsevier, 2017.

4. Commission on Dental Accreditation. Accreditation standards for dental education programs. 2018. At: ada.org/ / media/CODA/Files/pde.pdf. Accessed 16 Nov. 2018.

5. Tyagi P, Dodwad V, Kumar P, et al. Significance of ethics in dental education and professionalism: an insight on present scenario. Univ Res J Dent 2014;4:78-81.

6. Kuh GD, Whitt EJ. The invisible tapestry: culture in American colleges and universities. Washington, DC: ERIC-ASHE, 1988.

7. Stephens JD. Dental ethics: professional challenges in a changing world. J Calif Dent Assoc 2013;41:490-2.

8. MacEntee MI, Kazanjian A, Kozak JF, et al. A scoping review and research synthesis on financing and regulating oral care in long-term care facilities. Gerodontol 2012;29(2):e41-52.

9. Pham MT, Rajić A, Greig JD, et al. A scoping review of scoping reviews: advancing the approach and enhancing the consistency. Res Synthesis Methods 2014;5(4):371-85. 
10. Ousager J, Johannessen H. Humanities in undergraduate medical education: a literature review. Acad Med 2010;85(6):988-98.

11. Anyanwu EG. Background music in the dissection laboratory: impact on stress associated with the dissection experience. Adv Physiol Educ 2015;39(2):96-101.

12. Curtis EK. Why stories matter: applying principles of narrative medicine to health care ethics. J Am Coll Dent 2013;80(1):45-8.

13. Kieser J. Professional storytelling in clinical dental anatomy teaching. Anat Sci Educ 2008;1(2):84-9.

14. Krüger C, Blitz-Lindeque JJ, Pickworth GE, et al. Communication skills for medical/dental students at the University of Pretoria: lessons learnt from a two-year study using a forum theatre method. S Afr Fam Pract 2005;47(6):60-5.

15. Brett-MacLean P, Yiu V, Farooq A. Exploring professionalism in undergraduate medical and dental education through forum theatre. J Learn Through Arts 2012; $8(1): 1-13$.

16. Bourke LF. The use of theatre in dental health education. Aust Dent J 1991;36(4):310-1.

17. Al-Ahmad HT. Dental students' perception of theaterbased learning as an interactive educational tool in teaching oral surgery in Jordan. Saudi Med J 2010;31(7):819-25.

18. Schwartz B, Bohay R. Can patients help teach professionalism and empathy to dental students? Adding patient videos to a lecture course. J Dent Educ 2012;76(2):174-84.

19. Brocklehurst PR. Personal construct psychology: a theory to help understand professional development, a philosophy to support it. Prim Dent Care 2010;17(4):179-87.

20. Shefrin AP. The use of role-playing for teaching professionalism and ethics. J Dent Educ 1978;42(3):150-2.

21. Morton NA. Benefits of a humanistic education: a student perspective. J Dent Educ 2008;72(1):45-7.

22. Zahra FS, Dunton K. Learning to look from different perspectives: what can dental undergraduates learn from an arts and humanities-based teaching approach? Br Dent J 2017;222(3):147-50.

23. Quick KK. A humanistic environment for dental schools: what are dental students experiencing? J Dent Educ 2014;78(12):1629-35.

24. Quick KK. Conversation salons: a flexible format for open discourse in dental education. J Dent Educ 2016;80(4):466-72.

25. Nelson LP. Early performance in a humanistic medicine course as a predictor of dental students' later clinical performance. J Dent Educ 2013;77(8):1006-12.

26. Lyon L, Itaya LE, Hoover T, et al. Humanism in dental education: a comparison of theory, intention, and stakeholder perceptions at a North American dental school. J Dent Educ 2017;81(8):929-36.

27. Nadershahi NA. Building a humanistic culture in dental education. J Dent Educ 2017;81(10):1151-2.

28. Carey JA, Madill A, Manogue M. Communications skills in dental education: a systematic research review. Eur J Dent Educ 2010;14:69-78.

29. Rosenblum AB, Wolf S. Dental ethics and emotional intelligence. J Am Coll Dent 2014;81(2):26-35.

30. Victoroff KZ, Boyatzis RE. What is the relationship between emotional intelligence and dental student clinical performance? J Dent Educ 2013;77(4):416-26.
31. Hannah A, Lim BT, Ayers KMS. Emotional intelligence and clinical interview performance of dental students. J Dent Educ 2009;73(9):1107-17.

32. Pau A, Rowland ML, Naidoo S, et al. Emotional intelligence and perceived stress in dental undergraduates: a multinational survey. J Dent Educ 2007;71(2):972-81.

33. Munz LK. Implications of state dental board disciplinary actions for teaching dental students about emotional intelligence. J Dent Educ 2016;80(1):14-22.

34. Orsini CA, Jerez OM. Establishing a good dentist-patient relationship: skills defined from the dental faculty perspective. J Dent Educ 2014;78(12):1405-15.

35. Madhan B. Sense of humor and its association with psychological disturbances among dental students in India. J Dent Educ 2013;77(10):1338-44.

36. Morris RT, Sherlock BJ. Decline of ethics and the rise of cynicism in dental school. J Health Social Behav 1971;12(4):290-9.

37. Nash DA. The profession of dentistry: the University of Kentucky's curriculum in professional ethics. J Am Coll Dent 1996;63(1):25-9.

38. Chaves JF. Assessing ethics and professionalism in dental education. J Indiana Dent Assoc 2000;79(1):16-21.

39. Ozar DT. Dental ethics as an intellectual discipline: taking the next step. J Am Coll Dent 2000;67(1):30-4.

40. Berk NW. Teaching ethics in dental schools: trends, techniques, and targets. J Dent Educ 2001;65(8):744-50.

41. Zarkowski P, Graham B. A four-year curriculum in professional ethics and law for dental students. J Am Coll Dent 2001;68(2):22-6.

42. Spike JP. Developing a medical humanities concentration in the medical curriculum at the University of Rochester School of Medicine and Dentistry, Rochester, New York, USA. Acad Med 2003;78(10):983-6.

43. Welie JV. The ethics of roles. J Am Coll Dent 2003;70(3): 45-9.

44. Bertolami CN. Why our ethics curricula don't work. J Dent Educ 2004;68(4):414-25.

45. Sharp HM, Kuthy RA, Heller KE. Ethical dilemmas reported by fourth-year dental students. J Dent Educ 2005;69(10):1116-22.

46. Nash DA. On ethics in the profession of dentistry and dental education. Eur J Dent Educ 2007;11(2):64-74.

47. Schwartz AB, Peterson EM, Edelstein BL. Under oath: content analysis of oaths administered in ADA-accredited dental schools in the United States, Canada, and Puerto Rico. J Dent Educ 2009;73(6):746-52.

48. Erratt TD. Ethics education in undergraduate pre-health programs: the contribution of undergraduate colleges and universities to the ethical and moral development of future doctors in the medical and dental professions. Tex Dent $\mathrm{J}$ 2011;128(8):698-706.

49. Al-Zain SA, Al-Sadhan SA, Ahmedani MS. Perceptions of BDS students and fresh graduates about significance of professional ethics in dentistry. J Pak Med Assoc 2014;64(2):118-23.

50. Ilguy M. Ethical decision making in dental education: a preliminary study. BMC Med Ethics 2015;16:52.

51. Masella RS. Renewing professionalism in dental education: overcoming the market environment. J Dent Educ 2007;71(2):205-16. 
52. Christen AG, Christen JA. An ethical lesson learned from the equestrian sculpture "The Torch Bearers" at the University of Madrid dental school. J History Dent 2007;55(3):160-4; discussion 171-85.

53. Al-Johany S. Correlation between handwriting, drawing skills, and dental skills of junior dental students. J Contemp Dent Pract 2011;12(5):327-32.

54. American Dental Education Association. ADEA statement on professionalism in dental education. J Dent Educ 2018;82(7):774-8.

55. Gordon J. Medical humanities: to cure sometimes, to relieve often, to comfort always. MJA 2005;182:5-8.

56. Boudreau JD, Fuks A. The humanities in medical education: ways of knowing, doing, and being. J Med Humanit 2015;36(4):321-36.

57. Downie R. The role of literature in medical education: a commentary on the poem "Roswell, Hangar 84." J Med Ethics 1999;25:529-31.

58. Lovas JG, Lovas DA, Lovas PM. Mindfulness and professionalism in dentistry. J Dent Educ 2008;72(9):998-1009.

59. Vergnes JN, Apelian N, Bedos C. What about narrative dentistry? J Am Dent Assoc 2015;146(6):398-401.

60. Oakley M, Spallek H. Social media in dental education: a call for research and action. J Dent Educ 2012;76(3): 279-87.

61. McAndrew M, Johnston AE. The role of social media in dental education. J Dent Educ 2012;76(11):1474-81.

62. Spallek H, Turner SP, Donate-Bartfield E, et al. Social media in the dental school environment, part A: benefits, challenges, and recommendations for use. J Dent Educ 2015;79(10):1140-52.

63. Spallek H, Turner SP, Donate-Bartfield E, et al. Social media in the dental school environment, part B: curricular considerations. J Dent Educ 2015;79(10):1153-66.
64. Patrick AC. A review of teaching ethics in the dental curriculum: challenges and future developments. Eur J Dent Educ 2017;21(4):e114-8.

65. Gruppen L, Rytting M, Marti K. The educational environment. In: Dent J, Harden R, Hunt D. A practical guide for medical teachers. 5th ed. Amsterdam: Elsevier, 2017.

66. Murdoch-Kinch CA, Duff RE, Ramaswamy V, et al. Climate study of the learning environment for faculty, staff, and students at a U.S. dental school: foundation for culture change. J Dent Educ 2017;81(10):1153-63.

67. Karimbux NY. Creating a culture of academic integrity and professionalism. J Dent Educ 2016;80(1):3-4.

68. Koletsi-Kounari H. Penalties for academic dishonesty in a Greek dental school environment. J Dent Educ 2011;75(10):1383-9.

69. You D, Bebeau MJ. Gender difference in ethical abilities of dental students. J Dent Educ 2012;76(9):1137-49.

70. da Graça Kfouri M, Moysés ST, Gabardo MCL, Moysés SJ. Gender differences in dental students' professional expectations and attitudes: a qualitative study. Br Dent J 2017;22223(6):441-5.

71. Hillenburg KL, Murdoch-Kinch CA, Kinney JS, et al. LGBT coverage in U.S. dental schools and dental hygiene programs: results of a national survey. J Dent Educ 2016;80(12):1440-9.

72. Feng X, Mugayar L, Perez E, et al. Dental students' knowledge of resources for LGBT persons: findings from three dental schools. J Dent Educ 2017;81(1):22-8.

73. Anderson JI, Patterson AN, Temple HJ, et al. Lesbian, gay, bisexual, and transgender (LGBT) issues in the dental school environment: dental student leaders' perceptions. J Dent Educ 2009;73(1):105-18.

74. Calabrese LH. Sir William Osler then and now: thoughts for the osteopathic profession. J Am Osteopath Assoc 2005;105(5):245-9. 